\title{
RANCANG BANGUN MESIN PENGUPAS BIJI METE (ANACARDIUM OCCIDENTALE ) MENGGUNAKAN SISTEM PNEUMATIK
}

\author{
Muhammad Devi, Suyadi, Kunto Purbono \\ Program Studi D3 Teknik Mesin Jurusan Teknik Mesin Politeknik Negeri Semarang \\ Jl. Prof. H. Sudarto, S.H., Tembalang, Kotak Pos 6199/SMS, Semarang 50329 \\ Telp. 7473417, 7466420 (Hunting), Fax. 7472396
}

\begin{abstract}
Abstrak
Kacang mete adalah salah satu komoditas yang digunakan untuk pembuatan beberapa macam bahan baku makanan. Untuk menghasilkan kacang mete, terlebih dahulu harus mengupas biji mete, dari dulu pengupasan ini dilakukan dengan menggunakan alat yang dinamakan kacip yaitu alat yang masih tradisional dan penggunaannya sendiri masih dalam skala produksi kecil. Dengan menggunakan kacip dalam proses pengupasannya sebelumnya dapat menghasilkan $4 \mathrm{~kg} / \mathrm{jam}$. Maka untuk meningkatkan produktifitas, merancang mesin pengupas biji mete menggunakan sistem pneumatik. Metode perancangan yang dilakukan yaitu mencari referensi, membuat sketsa gambar, perhitungan gaya tekan pada mete, perhitungan pada poros, perhitungan diameter silinder, pembuatan komponen, perakitan komponen, pengujian mesin, dan spesifikasi mesin. Dengan menggunakan mesin ini diharapkan pengupasan biji mete dapat dilakukan secara otomatis. Dari hasil pengujian mesin pengupas biji mete didapatkan spesifikasi, panjang $670 \mathrm{~mm}$, lebar $500 \mathrm{~mm}$, tinggi $600 \mathrm{~mm}$, tekanan kompresor 8 bar, gaya tekan mete $24 \mathrm{~N}$, dan kapasitas mesin $6 \mathrm{~kg} / \mathrm{jam}$.
\end{abstract}

Kata Kunci : "mesin penanam bibit”, "mesin pengupas biji mete”, "pneumatik”

\section{Pendahuluan}

Jambu mete (anacardium occidentale) merupakan sebuah tanaman yang tumbuh subur di dataran rendah dan sedang. Terdapat dua bagian dalam tanaman ini yaitu buahnya sendiri yang sering kita sebut sebagai jambu monyet dan biji bercangkang yang disebut biji mete. Biji mete dapat dikonsumsi sebagai makanan kecil (snack) serta bahan baku pada industri makanan. Selain rasa yang lezat, kacang mete mengandung zat dan mineral yang baik bagi tubuh, antara lain menurut Haryadi dan Saragih (1994) persentase dari bagian-bagian buah mete gelondong adalah sebagai berikut:

- Kulit buah mete gelondong : $45-50 \%$

- CNSL : $18-23 \%$

- Kulit ari $: 2-5 \%$

- Biji Mete : $20-35 \%$

Selain penjelasan di atas, kulit keras buah mete gelondong mengandung air sebesar $13,17 \%$, abu $6,74 \%$, cellulose $17,35 \%$, protein $4,06 \%$, gula $20,85 \%$, dan CNSL $35,10 \%$. (Ohler, 1979).
Berdasarkanhaltersebut, tidak heran jika setiap tahunnya kebutuhan akan kacang mete selalu betambah. Kebutuhan yang tinggi akan kacang mete tidak diimbangi dengan produksi kacang mete yang baik, utuh dan berkualitas. Biji mete menjadi salah satu komoditi export yang persyaratan mutu-nya terdapat pada standard perdagangan Indonesia.

Untuk dapat menghasilkan biji mete yang berkualitas terdapat beberapa tahap dalam mengolahnya. Salah satu tahap untuk menghasilkan biji mete yaitu pengupasan cangkang mete dengan biji mete. Selama ini pengupasan biji mete masih dilakukan secara manual dengan kacip. Kacip merupakan alat sederhana alat tradisional yang dilengkapi dengan dua buah pisau pisau berpasangan. Biji mete gelondong diletakkan di atas landasan (bagian perut meghadap ke atas dan bagian punggung di bawah) dipukul satu persatu dari atas dengan sebuah kayu.Namun,dengan cara ini persentase biji mete yang pecah terbelah masih relative tinggi dan masih membutuhkan waktu yang 
relatif lama untuk menghasilkan jumlah kacang mete yang banyak.

Sangat sulit mendapatkan biji mete secara utuh dengan persentase yang tinggi menggunakan kacip. Banyaknya kacang mete yang tersortir akibat tidak memenuhinya kriteria kacang mete berkualitas, maka kebutuhan kacang mete tidak sebanding dengan produksinya.

Oleh karena itu, perlu adanya teknologi tepat guna yang menggantikan proses manual (tenaga manusia) dengan alat mekanik yang dapat mempercepat dan mempermudah dalam pengolahan biji mete sehingga mendapatkan biji mete yang diinginkan sesuai kebutuhan dalam jumlah yang banyak, yaitu dengan mesin pengupas biji mete (anacardium occidentale) menggunakan sistem pneumatik.

( R.S. Khurmi, 2005 : 517 )

\section{Metode Penelitian}

Penelitian dilakukan untuk mangetahui keberhasilan secara fungsional maupun operasional perancangan dan pembuatan mesin pengupas biji mete (annacardium occidentale) menggunakan sistem pneumatik, apabila ada kekurangan maka mesin inidapat diperbaiki dan disempurnakan kembali sehingga tujuan pembuatan mesin pengupas biji mete (annacardium occidentale) menggunakan sistem pneumatik dapat tercapai.

\section{Tujuan Pengujian}

Tujuan pengujian rancang bangun "Mesin Pengupas Biji Mete (Anacardium Occidentale) Menggunakan Sistem Pneumatik" ini adalah sebagai berikut :

- Mengatahui secara langsung apakah "Mesin Pengupas Biji Mete (Anacardium Occidentale) Menggunakan Sistem Pneumatik" telah dapat berfungsi dengan baik sesuai dengan yang direncanakan.
- Melakukan perbaikan jika terjadi kesalahan dan melakukan penyempurnaan jika mesin pengupas biji mete (annacardium Occidentale) menggunakan sistem pneumatik telah bekerja sesuai yang diharapkan.

- Untuk mendapatkan data-data yang diperlukan guna mengetahui karakteristik dari mesin tersebut.

- Dapat menarik suatu kesimpulan hasil pengujian dengan membandingkan teori dan keadaan di lapangan.

\section{Proses Pengujian}

Cara pengoperasian mesin pengupas biji mete (anacardium occidentale) menggunakan sistem pneumatik, sebagai berikut :

- Mengatur besarnya tekanan udara yang dibutuhkan untuk proses pengupasan biji mete.

- Pastikan rangkaian terpasang dengan benar sehingga tidak terjadi kebocoran udara.

- Hubungkan adapterelektrical ke sumber arus.

- Hidukan mesin dengan menekan tombol start.

- Amatilah hasil dari pengupasan biji mete dan dicatat sebagai data.

\section{Prinsip Kerja}

Adapun prinsip kerja dalam mesin pengupas biji mete (anarcadium occidentale) menggunakan sistem pneumatik yaitu :

- Siapkan biji mete yang sebelumnya sudah disangrai.

- Masukan biji mete kedalam box penampung bji mete.

- Hubungkan adapter ke sumber arus.

- Tekan saklar ON, maka posisi semua komponen standby. 
- Tekan tombol START untuk memulai langkah pengoperasian mesin.

- Setelah dikupas mete masuk ke dalam ember melewati corong.

Pada saat tombol startditekan, silinder A akan bergerak majumendorong biji mete yang kemudian masuk ke magazin, biji mete jatuh dari magazin menuju stoper, pisau pendorong maju digerakkan silinder $B$ menuju pisau potong, pisau potong berputar $30^{\circ}$ karena dorongan dari silinder $\mathrm{C}$, biji mete terkupas dan jatuh di plat peluncur kemudian masuk ke ember penampungan.

\section{Analisis}

Hasil pengujian mesin pengupas biji mete (anacrdium occidentale) menggunakan sistem pneumatik. Dari beberapa hasil pengujian yang telah dilakukan dengan biji mete yang sudah disangrai, didapatkan data sebagi berikut :

Tabel.1 Hasil pengujian pengupasan biji mete.

\begin{tabular}{|c|c|c|c|c|c|}
\hline 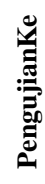 & 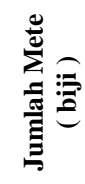 & 馬 & 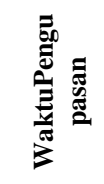 & 竘 & 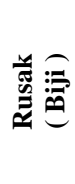 \\
\hline 1 & 10 & 0,08 & 50 detik & 3 & 7 \\
\hline 2 & 15 & 0,10 & 65 detik & 5 & 10 \\
\hline 3 & 20 & 0,16 & 72 detik & 6 & 14 \\
\hline
\end{tabular}

Analisis data :

Pengujian ke - 1

- Presentase produk biji mete dalam kondisi baik

$$
\begin{aligned}
& =\frac{\text { biji kondisi baik }}{\text { jumlah biji mete }} \times 100 \% \\
& =\frac{3}{10} \times 100 \%=30 \%
\end{aligned}
$$

- Presentase produk biji mete dalam kondisi rusak

$=\frac{\text { biji kondisi rusak }}{\text { jumlah biji moto }} \times 100 \%$ $=\frac{7}{10} \times 100 \%=70 \%$

Pengujian ke - 2

- Presentase produk biji mete dalam kondisi baik

$$
\begin{aligned}
& =\frac{\text { biji kondisi baik }}{\text { jumlah biji mete }} \times 100 \% \\
& =\frac{5}{15} \times 100 \%=33,33 \%
\end{aligned}
$$

- Presentase produk biji mete dalam kondisi rusak

$$
\begin{aligned}
& =\frac{\text { biji kondisi rusak }}{\text { jumlah biji mete }} \times 100 \% \\
& =\frac{10}{15} \times 100 \%=66,67 \%
\end{aligned}
$$

Pengujian ke -3

- Presentase produk biji mete dalam kondisi baik

$$
\begin{aligned}
& =\frac{\text { biji kondisi baik }}{\text { jumlah biji mete }} \times 100 \% \\
& =\frac{6}{20} \times 100 \%=30 \%
\end{aligned}
$$

- Presentase produk biji mete dalam kondisi rusak

$$
\begin{aligned}
& =\frac{\text { biji kondisi rusak }}{\text { jumlah biji mete }} \times 100 \% \\
& =\frac{14}{20} \times 100 \%=70 \%
\end{aligned}
$$

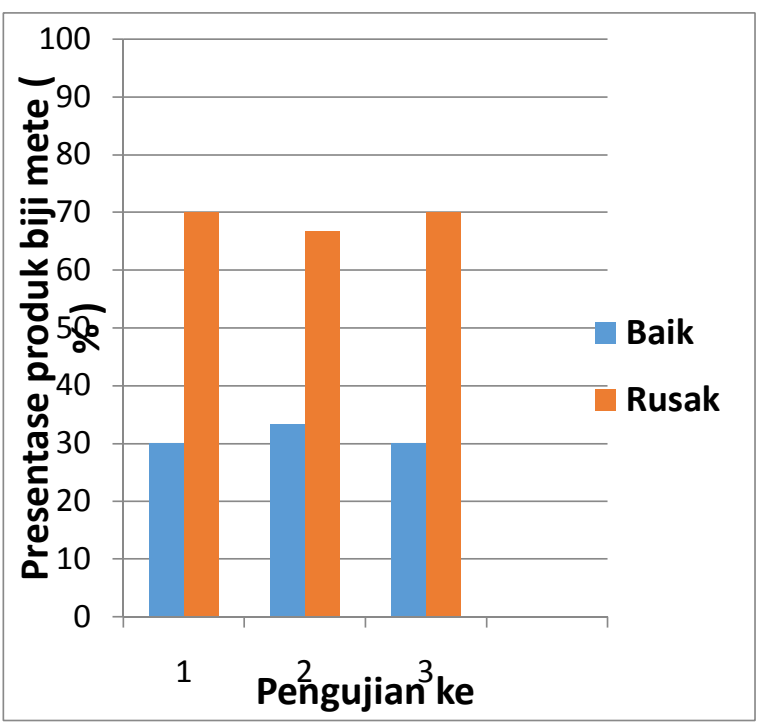

Gambar 1. Grafik pengujian 
Jadi, dapat disimpulkan dari pengujian ke 1, 2, dan 3 presentase produk biji mete dalam kondisi rusak lebih besar dibandingkan dengan produk biji mete dalam kondisi yang baik.

Keterangan : Spesifikasi biji mete rusak dan baik

Biji Mete rusak

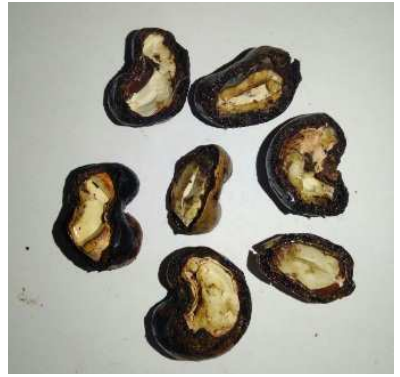

\section{Gambar 2. Biji Mete Rusak}

Biji Mete baik

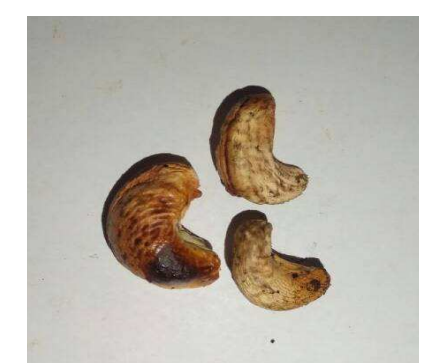

\section{Gambar 3. Biji Mete Baik}

\section{Analisis Hasil Penelitian}

Berdasarkan hasil pengujian pengupasan yang dilakukan dapat dianalisis beberapa hal yang menyebabkan biji mete rusak lebih banyak daripada biji mete baik, yang diakibatkan oleh beberapa faktor antara lain:

- Ukuran biji mete yang bervariasi dapat menyebabkan biji mete yang besar menyangkut pada magazine dan jika biji mete terlalu kecil pada saat biji mete jatuh di stoper, posisi biji mete horizontal apabila posisi mete horizontal pada saaat pengupasan biji mete akan langsng rusak. Jadi biji mete harus disortir terlebih dahulu, agar biji mete tidak menyangkut didalam magazine.
- Jarak antara ujung pisau pemotong sangat berpengaruh pada hasil pengujian, jika jarak terlalu jauh maka biji mete tidak dapat dikupas dan jika jarak terlalu deket maka biji mete langsung hancur. Pada saat pengujian kita menggunakan beberapa jarak pisau antara lain, $10 \mathrm{~mm}$, dan $5 \mathrm{~mm}$. pada jarak pisau $10 \mathrm{~mm}$ biji mete belum mampu terkupas karena jaraknya terlalu jauh. Pada jarak pisau $5 \mathrm{~mm}$ biji mete dapat terkupas karena jarak antar pisau dengan biji mete sudah tepat.

- Pisau potong tidak mampu berputar $30^{\circ}$ agar biji mete mampu terbelah menjadi dua, dikarenakan tekanan pada silinder peneumatik $\mathrm{C}$ tekananya kurang besar, dan pisau potong hanya mampu berputar $15^{\circ}$. Agar pisau potong dapat berputar secara maksimal $30^{\circ}$ diameter silinder pneumatik harus lebih besar.

- Biji mete disangrai bertujuan untuk mengurangi kadar minyak yang terdapat pada biji mete, agar silinder $\mathrm{C}$ mampu memutar pisau putar.

\section{Analisis Pada Mesin}

Analisis pada mesin dilakukan karena ada beberapa faktor masalah yang dihadapi pada saat mesin beroperasi, yaitu :

- Silinder pneumatik C

Tekanan silinder secara teoritis dari perhitungan mampu memutar poros pisau, sedangkan aktualnya silinder pneumatik C tidak mampu memutar poros pisau. Dikarenakan diameter silinder peneumatik kurang besar. Agar silinder pneumatik mampu memutar poros pisau secara maksimal diameternya harus diberi yang lebih besar.

- Pisau

Berdasarkan profil pisau dan hasilnya 
Model Pisau A.

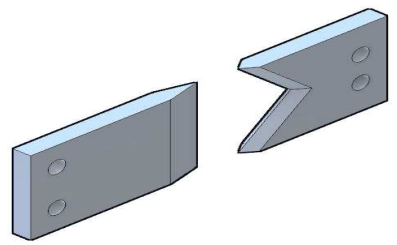

Gambar 4. Model Pisau A

Keterangan : Biji mete langsung hancur.

- Model Pisau B

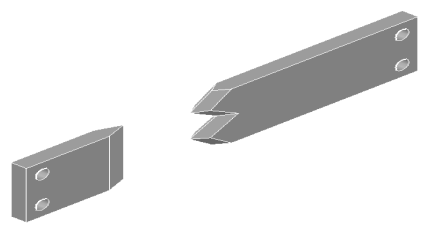

\section{Gambar 5. Model Pisau B}

Keterangan : Biji mete kemungkinan terbaik.

\section{Kesimpulan}

Berdasrkan dari seluruh proses pembuatan Tugas Akhir ini yaitu mendesain mesin, merancang mesin, proses pembuatan, perakitan, dan pengujian dapat disimpulkan sebagai berikut :

- Rancang bangun telah diwujudkan dalam naskah Tugas akhir dengan judul "Rancang Bangun Mesin Pengupas Biji Mete (Anacardium Occidentale) Menggunakan Sistem Pneumatik".

- Rancang bangun mesin pengupas biji mete (anacardium occidentale) menggunakan system pneumatik, dengan spesifikasi mesin sebagai berikut :

$\begin{array}{lll}\text { Panjang } & =670 & {[\mathrm{~mm}]} \\ \text { Lebar } & =50 & {[\mathrm{~mm}]} \\ \text { Tinggi } & =600 & {[\mathrm{~mm}]}\end{array}$

Tekanan kompresor $=8$ [bar $]$

Gaya tekan mete $=24 \quad[\mathrm{~N}]$

Jumlah pisau Pendoron $\mathrm{g}=2 \quad$ [buah]

Jumlah pisau putar $=2$ [buah]

Kapasitasmesin $=6[\mathrm{Kg} / \mathrm{jam}]$

- PengujianHasilPengupasan

Dari pengujian yang dilakukan didapatkan hasil, 30\% biji mete dalam kondisi baik dan $70 \%$ biji mete dalam kondisi rusak.

\section{Daftar Pustaka}

- G. Budynass, R., \& J. Keith Nisbett. 2011. Shigley's Mechanical Engineering Design Ninth Edition. New York: McGraw Hill.

- Khurmi, R., \& K. Gupta J. 2005. A Textbook of Machine Design. New Delhi: Eurasia Publishing Housing (PVT). Ltd, Ram Nagar.

- Sularso, Ir. MSME., Kiyokatsu Suga. 1985. Dasar Perencanaan dan Pemilihan Elemen Mesin. Jakarta: Pradnya Paramita.

- Scharkus, Herman Jutz\& Eduard. 1985. Westermann Tables. New Delhi: Wiley Eastern Ltd.

- Sugiarto, G. Taksehi Sato \& Hartanto. 1986. Menggambar Mesin Menurut Standart ISO. Jakarta: Pradaya Paramita.

- Technical Drawing ISO Standards Hand Book, Switzerland 1991.

- https://id.123dok.com//document/lzgkgw8 y-modifikasi-dan-ujiperformansi-alatpengupas-kulit-buah-metegelondong-anacardium-accidentale1.html(diakses 29 Maret 2018, Pukul 16.25).

- http://shofianriyaldi21.blogspot.co.id/201 5/10/definisi-sistempneumatik.html(diakses tanggal 25 Mei 2018, pukul 14.10).

- https://id.wikipedia.org/wiki/Pneumatik(di akses tanggal 5 Juni 2018, pukul 20.56).

- http://dunia-

listrik.blogspot.co.id/2010/02/dasardasar-pneumatik.html(diakses tanggal 6 Juni 2018, pukul 19.00). 